\title{
AN INNOVATIVE FEA METHODOLOGY FOR MODELING FASTENERS
}

\author{
MacArthur L. Stewart ${ }^{1}$ \\ ${ }^{1}$ Assistant Professor, Mechanical Engineering Technology Department, Eastern Michigan University, MI, USA
}

\begin{abstract}
Abstract-Researchers have developed finite element analysis (FEA) modeling methods to simulate the mechanical behavior of bolts in bolted joints. The most commonly used FEA bolt modeling methods are the spider and solid bolt models. The spider bolt model uses $1 D$ elements to simulate the bolt's mechanical behavior. This approach is computationally efficient but does not consider contact at the fastener-joint interface. However, contact at the fastener-joint interface is considered in the solid bolt model which uses 3D finite elements to discretize the geometry of the bolt, which increases the computational expense of the FEA model. In this work, an innovative FEA bolt modeling method is presented that is both computationally efficient and considers the actual geometry of the fasteners. Specifically, commercially available FEA software was used to construct a structural model of a clevis type bracket that was bolted to a rigid wall to simulate bolt pretension and the bracket's response to an externally applied axial force. Mating surface contact was considered and the actual geometry of the fastener was modeled as force controlled rigid surfaces. The predicted contact stress at the bolt-joint interface, after bolt pretension was simulated, correlated with the analytically calculated surface pressure to within $13.5 \%$. After the external axial force was applied, the predicted maximum bending stress at the top and bottom of the section of interest correlated with the analytically calculated values to within $5.2 \%$ and $8.8 \%$, respectively. Further investigation (experimental) is planned to study the contact stress distribution over the mating part contact areas.
\end{abstract}

Keywords: bolted joint, machine component design, bolt FEA

\section{INTRODUCTION}

Threaded fasteners (screws, nuts and bolts) are common machine components that are used to connect structural members, Fig -1. Understandably, joint failure can be catastrophic, resulting in economic and/or human losses. The primary function of threaded fasteners is to create a clamping force between two or more joint members that are bolted together. In other words, bolted joints behave like springs in series; the bolt stretches and the joint members compress [1]. Fig -2 shows the basic thread profile for the metric and unified (inch) screw systems. The included angle is $60^{\circ}$ and the thread roots are flat. For a given screw, a larger root radius may be used to mitigate the thread root stress concentration [2]. Note that as the thread root radius increases thread engagement decreases.

Prior to constructing a structural finite element analysis (FEA) model of a bolted joint, the design engineer must decide which of the primary bolt characteristics to model. Because of the length scale difference, it is generally not computationally efficient to model the thread profile. So, the remaining fundamental bolt characteristics that should be considered are pretension and mating part contact.

Researchers have developed FEA bolt modeling methods to simulate the mechanical behavior of bolts in bolted joints. For example, researchers investigated the efficacy of 4 different FEA methodologies for modeling the bolt mechanics in a bolted joint: a solid bolt model, coupled bolt model, spider bolt model, and no-bolt model [3]. They compared their FEA results to experimental test results. The solid bolt model which was discretized using hexahedral elements was shown to provide the most accurate results. From the perspective of both computational efficiency and accuracy, the coupled bolt model was show to be more effective.

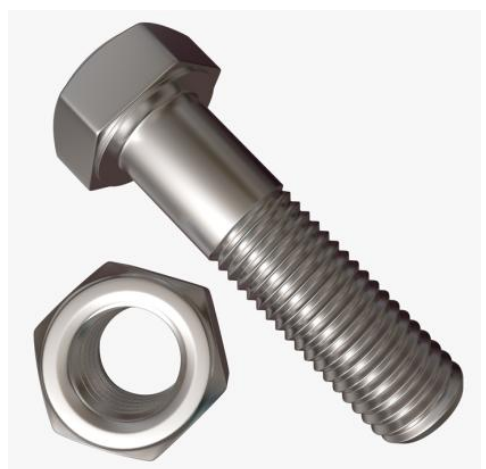

Fig -1: Example of a machine bolt and nut

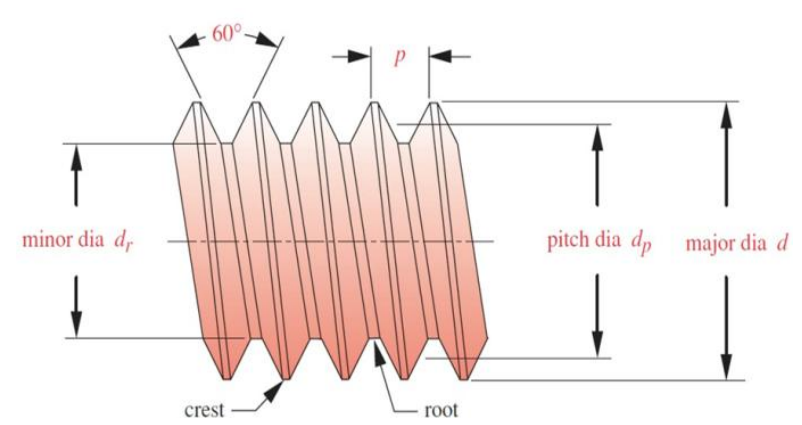

Fig -2: Profile of a standard screw thread 
Other investigators constructed an FEA model of a motorcycle fork screw clamp to calculate the stresses in both the joint members and screw [4]. Their intent was to derive empirical formulas that considered eccentric external loads. These researchers built a 3D FEA model of half the screw clamp using tetrahedral elements. The screw threads were not modeled and a thermal preload was used to model bolt tension. The predicted bolt bending stress correlated to within $7.3 \%$ of the analytically calculated value.

Scholars also constructed an FEA bolt model to validate a proposed analytical equation to predict the stiffness of a bolted joint [5]. These researchers developed a 2D FEA model of the bolted joint, the shank of the bolt was not included. The stiffness of the bolt head was made much larger ( 3 orders of magnitude greater) than the joint members. Compared to the FEA and experimental results, the analytical results correlated to within $2.7 \%$ and $14.7 \%$, respectively.

Besides simplifying the thread geometry, investigators considered modeling the actual geometry of the thread profile. For example, modeling the actual geometry of the bolt and nut threads with a partial model of the joint members was studied [6]. In addition to modeling the actual thread profile, other researchers modeled the bolt and nut as a single component [7].

In this investigation, an innovative FEA bolt modeling method is presented that is both computationally efficient and considers the actual geometry of the fasteners. Specifically, this paper investigated the efficacy of modeling the actual geometry of a bolt using load controlled rigid surfaces and using a contact algorithm to simulate contact between the mating parts. The proposed methodology was demonstrated on a clevis type bracket that was bolted to a rigid wall, Fig -3. The bracket was then subjected to bolt pretention followed by an externally applied axial load.

The following assumptions were considered in this study:

- The clevis bracket was manufactured from steel, $\mathrm{E}=$ $210 \mathrm{GPa}$ and $v=0.3$

- The clevis bracket was free from material and manufacturing defects

- The bolt and wall were stiffener than the bracket by several orders of magnitude

The major contributions to the published literature from this research include:

- An innovative structural FEA modeling methodology that models the fasteners as load (or displacement) controlled surfaces

- A computationally efficient FEA modeling methodology that includes mating part contact

- An innovative FEA modeling methodology for constraining bolted joints and calculating bolt reaction loads

\section{ANALYTICAL STRESS CALCULATIONS}

In this investigation, the predicted FEA results were verified by comparing them to analytical calculations. For the analytical calculations, Planar Mechanics of Materials principles were considered and the externally applied axial force was modeled as a concentrated force with its line of action directed through the center of the pin hole. From Fig 3 , the bending stress $\sigma$ was calculated at the section shown. After applying the equilibrium equations to the free body diagram (FBD), the analytical equation defining the corresponding bending stress $\sigma$ was

$$
\sigma=\frac{\mathrm{My}}{\mathrm{I}}=\frac{\left(\frac{\mathrm{F}}{2}\right) \mathrm{L}\left(\frac{\mathrm{h}}{2}\right)}{\frac{1}{12} \mathrm{bh}^{3}}=\frac{3 \mathrm{FL}}{\mathrm{bh}^{2}} .
$$

At this section, the geometry was rectangular with a $40 \mathrm{~mm}$ and $5 \mathrm{~mm}$ base (b) and height (h), respectively. The perpendicular distance (L) between the line of action of the concentrated force $(\mathrm{F})$ and the centroid of the section was 10 $\mathrm{mm}$.

For the bearing stress (surface pressure) calculation, the bolt flange and bolt hole diameters were $20.8 \mathrm{~mm}$ and $10.5 \mathrm{~mm}$, respectively.

$$
\sigma_{\text {bearing }}=\frac{\text { Clamp Load }}{A_{\text {bearing }}} .
$$
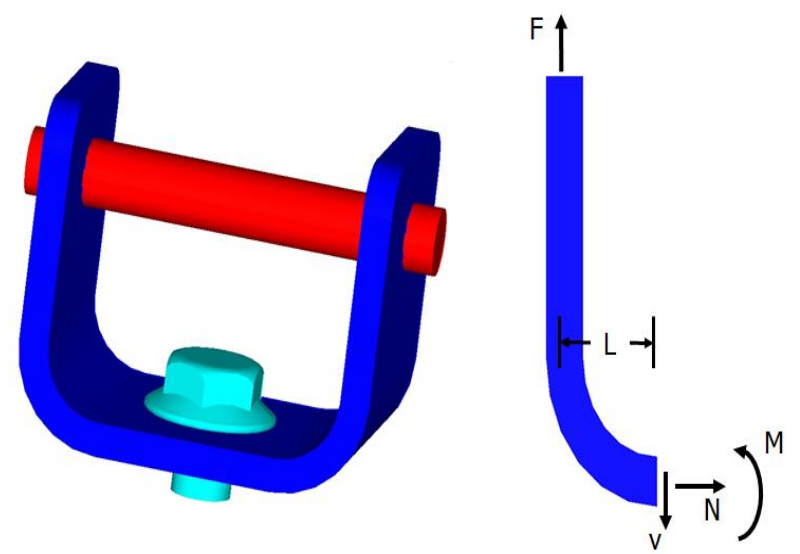

Fig -3: Clevis bracket assembly: CAD data (left) and FBD exposing the internal reaction loads at the section of interest (right)

\section{FEA METHODOLOGY}

In this work, two commercially available computer software programs were used as the primary research tools. 1) HyperMesh [8] was used to discretize the computational domain. HyperMesh is a FEA pre-processor, Altair Engineering, Inc. 2) Except for meshing, the FEA model was constructed and processed using MARC/Mentat which is a multi-purpose nonlinear FEA software package, MSC Software Corporation [9]. Fig -4 gives a general overview of the proposed FEA modeling methodology. This section contains a detailed description of how the FEA model of the 
clevis bracket was constructed. Section 3 is organized into 4 subsections: 1) geometry discretization, 2) material properties, 3) boundary conditions, and 4) numerical solution methods.

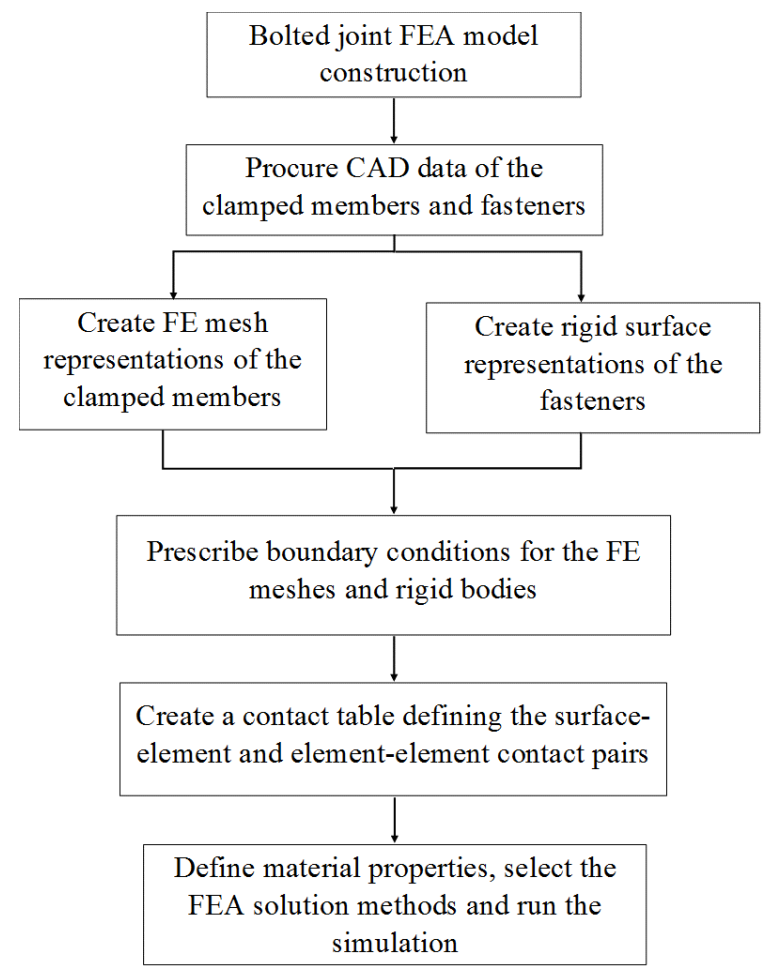

Fig -4: Overview of the proposed FEA modeling methodology

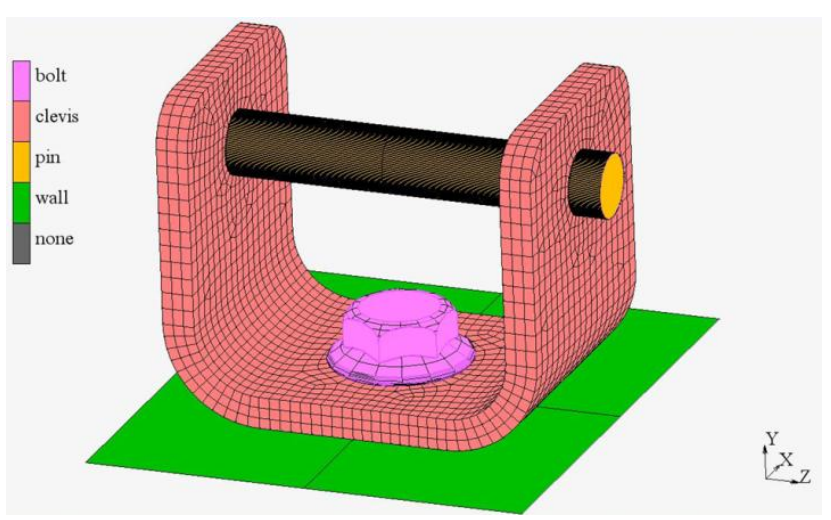

Fig -5: Bolted joint FEA model: hexahedral FEA mesh, rigid surface representations of the bolt, pin, and attaching wall

\subsection{Geometry Discretization}

Recall that the proposed FEA modeling methodology was demonstrated on a clevis type bracket that was bolted to a rigid wall, Fig -3 . The CAD data that represented the geometry of the clevis bracket was first imported into HyperMesh. 4,686 linear hexahedral elements were used to discretize the bracket, Fig -5 . Surfaces that represented the bolt were modeled as force controlled rigid surfaces. Note that the thread profile was not considered. Because of the length scale difference, discretizing the thread profile was not practical.

\subsection{Material Properties}

A linear constitutive relationship was assumed for this study. In other words, Hooke's Law was applicable. As mentioned before, the clevis bracket was assumed to be fabricated from steel with the following properties: $E=210$ GPa and $v=0.3$.

\subsection{Boundary Conditions}

A touching contact boundary condition was used to define the boundary nonlinearity between the mating parts. The rigid surface representing the wall was fixed. The pin and bolt surfaces remained fixed in the lateral directions. A point force, applied to the centroid of the bolt, was used to apply the prescribed bolt pretension. Similarly, a point load boundary condition was prescribed to the centroid of the pin surfaces to simulate the externally applied axial load.

\subsection{Numerical Solution Methods}

The numerical methods that were considered in this study are summarized here:

- Element Type: 4,686 $1^{\text {st }}$ order hexahedral elements

- Contact: touching contact between the mating part surfaces

- Boundary Conditions: Rigid surfaces, force controlled

- Dynamic Effects: none (quasi static)

- Solution Control: Large displacement, Lagrangian, New-Raphson

- $\quad$ Stepping Procedure: Constant time step

- Convergence Criteria: Relative residual force magnitude, criteria $\leq 0.1$

\section{RESULTS}

After constructing the FEA model of the clevis bracket, it was loaded in two phases: a $445 \mathrm{~N}(100 \mathrm{lb})$ bolt preload was followed by subjecting the bolted bracket to a $222.5 \mathrm{~N}$ (50 lb) axial force through the pin. In this section, the simulation results are presented. This section is organized into 2 subsections that shows how the proposed FEA modeling methodology correlated with the analytical calculations: 1) surface pressure (contact stress) correlation, and 2) bending stress correlation.

\subsection{FEA Model Correlation: Contact Stress}

After inserting the known values into equation (2), the calculated average bearing stress $\sigma_{\text {bearing }}$ (surface pressure) was $1.757 \mathrm{MPa}$. The distribution of the predicted surface pressure under the bolt head and at the rigid wall interface are shown on the contour plots in Fig. 6, top and bottom, respectively. Table 1 contains the predicted numeric values at specific locations from the inner diameter of the bolt hole (bolt head side). 


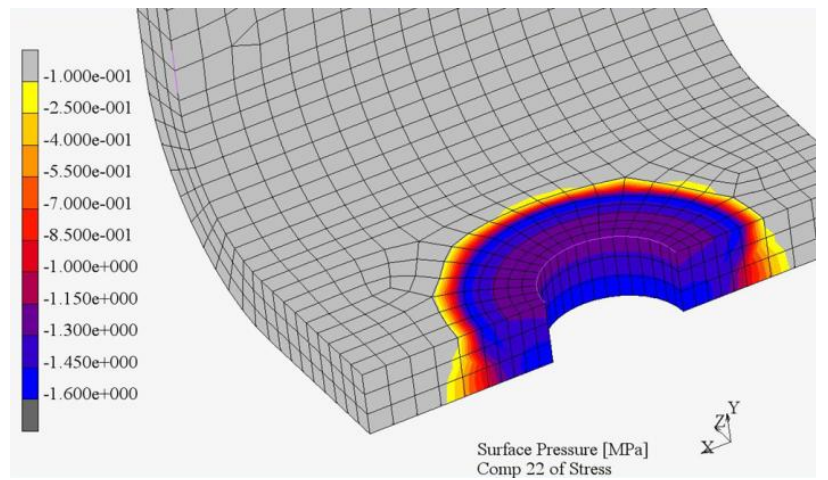

Fig -6: Contact stress distribution

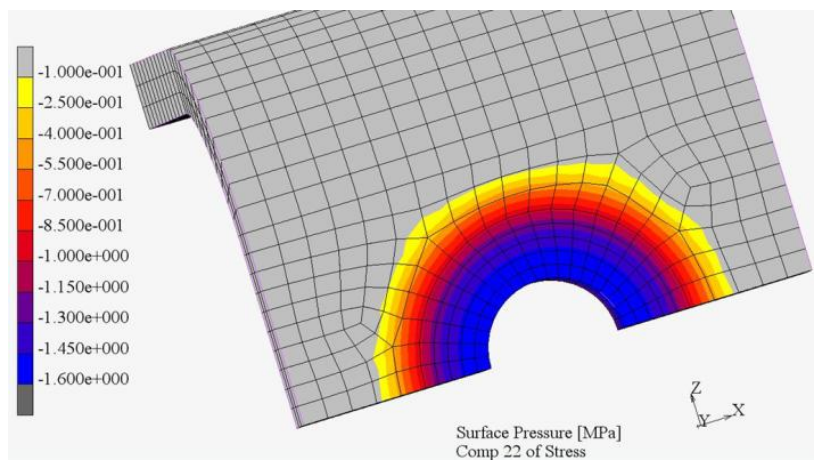

Fig -7: Bending stress distribution

Table -1: Surface Pressure distribution

\begin{tabular}{|c|c|}
\hline $\begin{array}{c}\text { Distance from the ID of the } \\
\text { Bolt Hole }[\mathrm{mm}]\end{array}$ & Surface Pressure [MPa] \\
\hline 0 & $1.19(\mathrm{C})$ \\
\hline 1.03 & $1.22(\mathrm{C})$ \\
\hline 2.06 & $1.25(\mathrm{C})$ \\
\hline 3.09 & $1.29(\mathrm{C})$ \\
\hline 4.12 & $1.41(\mathrm{C})$ \\
\hline 5.14 & $1.52(\mathrm{C})$ \\
\hline
\end{tabular}

Assuming that the contact surface of the bolt flange was parallel to the joint surface, the surface pressure distribution was expected to vary from a maximum directly under the bolt head and decrease as the distance from the bolt increased [1]. However, the results from this study showed that the surface pressure distribution varied from a minimum directly under the bolt head and increased as the distance from the bolt increased.

The author suspected that this phenomena was the result of the compliance ratio between the bolt and clevis bracket models. Since the stiffness of the bolted joint within the grip length is much smaller than bolt stiffness, the bolt preload subjected the bracket to a bending moment, compression on the bolt head side and tension on the wall interface side. In other words, the bolt hole tended to dilute. This observed phenomena will be experimentally studied in future work.

Note that the relative error between the maximum predicted contact stress, $1.520 \mathrm{MPa}$, and the analytically calculated value, $1.757 \mathrm{MPa}$, was $13.5 \%$.
At the bracket and wall interface, the surface pressure distribution trended as expected.

\subsection{FEA Model Correlation: Bending Stress}

After inserting the known values into equation (1), the calculated bending stress $\sigma_{\mathrm{zz}}=\sigma_{33}$ in the section of the bracket of interest was $\pm 6.68 \mathrm{MPa}$, compression at the top and tension at the bottom of the section. The bending stress contour plot of the bracket at this section is shown in Fig -7. The predicted bending stress ranges from $7.03 \mathrm{MPa}(\mathrm{C})$ at the top of the section to $6.09 \mathrm{MPa}(\mathrm{T})$ at the bottom, see Table 2.
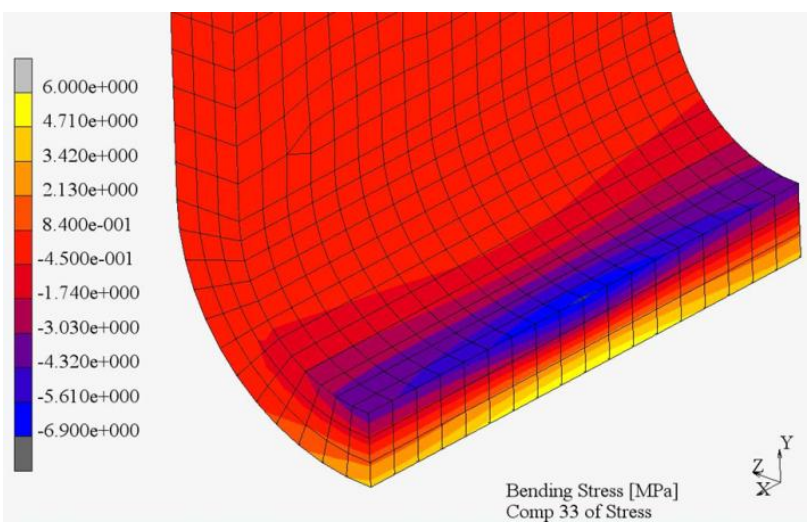

The author suggested that the bending stress magnitude difference at the top and bottom of the section resulted from the section being relatively close to the bolt hole and the application of the pretension force. The bolt hole and pretension force caused a localized increase in stress along the section, stress concentrations. In other words, SaintVenant's Principle was used to substantiate this hypothesis. According to Saint-Venant's Principle the stress magnitude difference would diminish as the distance between the section and location of the bolt hole increased.

Notice that the predicted maximum bending stress correlates with the analytically calculated values to within $5.2 \%$ and $8.8 \%$ at the top and bottom of the section, respectively.

Table -2: Bending stress distribution

\begin{tabular}{|c|c|}
\hline $\begin{array}{c}\text { Distance from the top of } \\
\text { the cross section }[\mathrm{mm}]\end{array}$ & Bending Stress $\sigma_{\mathrm{z}}[\mathrm{MPa}]$ \\
\hline 0 & $7.03(\mathrm{C})$ \\
\hline 1.7 & $3.11(\mathrm{C})$ \\
\hline 3.4 & $2.46(\mathrm{~T})$ \\
\hline 5 & $6.09(\mathrm{~T})$ \\
\hline
\end{tabular}

\section{DISCUSSION}

Machine component design engineers could use the proposed FEA methodology to design and evaluate bolted joints outside of the applicable range of analytical equations. For example, this methodology may be used to model bolt connections to predict the slip capacity of a bolted joint comprised of clamped members with complex geometries. 
In addition, it could be used to predict the contact stress between mating parts. Besides design evaluations, the proposed methodology may be used to support bolted joint failure analyses.

\section{CONCLUSION}

In conclusion, this research demonstrated that force controlled rigid surfaces representing the fasteners can be used to model the effects of pretension and mating part contact on a bolted joint. The proposed methodology was computationally efficient and the results correlated with reality. The predicted contact stress at the bolt-joint interface, after bolt pretension was simulated, correlated with the analytically calculated surface pressure to within $13.5 \%$. After the external axial force was applied, the predicted maximum bending stress at the top and bottom of the section of interest correlated with the analytically calculated values to within $5.2 \%$ and $8.8 \%$, respectively. In future work, the proposed FEA modeling methodology will be directly compared to previously published bolt modeling methods. Further investigation (experimental) is also planned to study the contact stress distribution over the mating part contact areas.

\section{REFERENCES}

[1]. J. Bickford, "An introduction to the design and behavior of bolted joints." New York: CRC Press; 1995.

[2]. R.C. Juvinall, K.M. Marshek. "Fundamentals of machine component design." New York: John Wiley and Sons; 1991.

[3]. K. Jeong, J.C. Yoon, B.S. Kang. "Finite element analysis and modeling of structure with bolted joints." Applied Mathematical Modeling, pp. 895-911, 31, March 2006.

[4]. D. Croccolo, M. De Agostinis, N. Vincenzi. "A contribution to the selection and calculation of screws in high duty bolted joints." International Journal of Pressure Vessels and Piping, pp. 38-48, May 2012.

[5]. N. Haidar, S. Obeed, M. Jawae. "Mathematical representation of bolted-joint stiffness: A New Suggested Model." Journal of Mechanical Science and Technology, 11, pp. 2827-2834, July 2011.

[7]. M. Pavlovic, Z. Markovic, M. Veljkovic, D. Budevac. "Bolted shear connectors vs. headed studs behavior in pushout tests" Journal of Construction Steel Research, pp 134149, May 2013.

[6]. C. Stocchi, P. Robinson, S.T. Pinho. "A detailed finite element investigation of composite bolted joints with countersunk fasteners." Composites: Part A, pp 143-150, October 2012.

[8]. Altair Engineering, "HyperMesh 12, User Manual." 2012.

[9]. MSC Software Corporation, "Volume A: theory and user Manual.” 2013. 